\title{
Gestational Trophoblastic Neoplasia
}

\author{
Mahmoud Ibrahim M. Shahin*, Wael Helmy El Sheshtawy, Mohsen Salah El-Din Zikri \\ Clinical Oncology and Nuclear Medicine Department, Faculty of Medicine, Al-Azhar University \\ * Corresponding author: Mahmoud Ibrahim M. Shahin, E-mail: Mahmoudshahin.s3@gmail.com
}

\begin{abstract}
Background: gestational trophoblastic neoplasia forms a wide variety of rare conditions arising from abnormal proliferation of the trophoblastic cells in the placental microvilli. They consist of vesicular mole "partial and complete", invasive mole, placental site trophoblastic tumor (PSTT), epithelioid trophoblastic tumor (ETT) and choriocarcinoma. They can be classified into premalignant forms which include vesicular mole and malignant forms which include the rest. Aim of the Work: this study aimed to study the epidemiological and clinical data, as well as treatment regimes and their outcome included response and related toxicity among patients with gestational trophoblastic neoplasia treated in this study.Patients and Methods: in this retrospective study, medical records of all patients with GTN presented to Oncology Department, Al-Hussein University Hospital in the period from January 2007 to June 2017 was retrieved from the archives and medical data was reviewed and analyzed. Results: median age of patient was 37.5 (Range 20-55), molar pregnancy was the most common pathological type (40\%), followed by invasive mole (31.4\%), while choriocarcinoma was diagnosed in $25.7 \%$ and only $2.9 \%$ of patients had placental site trophoblastic disease. According to FIGO score; 26 patients (74.3\%) showed low risk and 9 patients $(25.7 \%)$ showed high risk. In low risk patients, 30.8\% of patients were kept under follow up while, (69.2\%) received chemotherapy, $61.1 \%$ of them achieved complete remission on methotrexate as first line chemotherapy, while the rest $38.9 \%$ achieved complete response on EMA-CO or dactinomycin as $2^{\text {nd }}$ line chemotherapy. Methotrexate wasn't effective in high risk patients, while EMA-CO had much better response achieving (66.7\%) complete response rate, with 2 cases of early death in those patients. Conclusion: this retrospective study represented a single center experience and had relatively small number of cases. A large multicenter prospective trial is recommended.
\end{abstract}

Keywords: trophoblastic, neoplasia, microvilli, epithelioid trophoblastic.

\section{INTRODUCTION}

Gestational trophoblastic neoplasia forms a wide variety of rare conditions that arising due to abnormal proliferation of the trophoblastic cells in placental microvilli. They consist of vesicular mole "partial and complete", invasive mole, placental site trophoblastic tumor (PSTT), epithelioid trophoblastic tumor (ETT) and choriocarcinoma ${ }^{(1)}$. They can be classified into premalignant forms which include vesicular mole and malignant forms which include the rest ${ }^{(2)}$. During the 2000 Fédération Internationale de Gynéologie et d'Obstétrique (FIGO) Oncology Committee meeting held in Washington, it was recommended that gestational trophoblastic neoplasia (GTN) should replace terms like gestational trophoblastic tumor, persistent gestational trophoblastic disease (GTD), residual GTD and malignant GTD.Internationally incidence varies from country to another. In a recent cross-sectional study conducted during 2014 at Al-Azhar University hospital the overall incidence was 6.6 per 1,000 deliveries (150/22727) which were relatively higher than reports from different countries ${ }^{(3)}$. In USA they account for only less than $1 \%$ of all gynecological tumors accounting for about 1 pregnancy out of 1,000 in which vesicular mole was the most common while, choriocarcinoma were far less common affecting around 2 to 7 of every 100,000 pregnancies ${ }^{(4)}$. While, the Far East accounts for the highest incidence up to 40.2 per 1000 births for vesicular mole and 5 per 1,000 for choriocarcinoma. However more recent studies reported that incidence has fallen to 2 per 1000 and 0.5 per 1,000 ${ }^{(5)}$.After molar pregnancy evacuation there's no need for prophylactic chemotherapy just a regular follow up with B-hCG every 2 weeks can provide an accurate observational tool ${ }^{(6)}$. Where a plateaued or rising hCG, was an indication for starting chemotherapy. Also, a tissue diagnosis of choriocarcinoma or spread to other organs was indications for chemotherapy ${ }^{(7)}$. A sustained elevated HCG after 6 months even if decreasing is a controversial indication for chemotherapy (8). Despite the rarity of these diseases they're highly curable due to high sensitivity to chemotherapy with cure rates reaching up to $100 \%$ even with historical 
treatments for GTN (Hertz R et al. 1956). The continuous attempts now are to keep these high cure rates while minimizing unnecessary excess chemotherapy that may decrease future fertility ${ }^{(9)}$.For this purpose GTN can be practically subdivided into low risk group and high risk group according to the FIGO prognostic scoring system. Where patients were assessed based on age, result of previous conception, interval between its termination and onset of disease and pre-treatment assessment including B-hCG level, largest tumor size, site and number of metastasis and prior chemotherapy. Then they're grouped according to their score to either low risk (Score 0 to 6) or high risk (score >6) ${ }^{(\mathbf{1 0})}$. Low risk GTN can be treated only by a single agent chemotherapy "methotrexate and folinic acid or actinomycin-D" while high risk GTN requires combination chemotherapy EMA-CO "etoposide, methotrexate, actinomycin-D, cyclophosphamide, and vincristine" (11).

\section{AIM of the WORK}

This study aimed to evaluate epidemiological and clinical data, as well as treatment regimes and their outcome including response and related toxicity among patients with gestational trophoblastic neoplasia treated in this study.

\section{PATIENTS and METHODS}

In this retrospective study, all patients diagnosed with GTN presented to Oncology Department, Al-Hussein University Hospital in the period from January 2007 to June 2017 were included in this study. The study was approved by the Ethics Board of Al-Azhar University.

Patients, who missed before active treatment, received unknown chemotherapy outside our department or had double malignancy other than basal cell carcinoma, were excluded from the study. The medical files of included patients were reviewed and all data related to either patient, disease, treatment or response were retrieved and analyzed. Patients were classified according to pathological type into vesicular mole (partial, and complete), invasive mole, choriocarcinoma, or placental site trophoblastic disease; and into two risk groups based on FIGO prognostic scoring system in to low risk group (6 or less), or high risk group (7 or higher). Treatment response was assessed by using B-hCG level, where normalization of its level was considered complete remission, continues decrease in level was a sign of response, while a plateau for 3 consecutive readings or increasing in level of B-hCG considered disease resistance to treatment. Univariant analysis was done to determine risk factors related to resistance to first line chemotherapy. Survival interval was the time between the date of histological diagnosis and the date of the last follow-up (for censored observations) or the date of death (for uncensored observations).

\section{RESULTS}

Out of 10,119 cancer patients presented at Al Husien University Hospital during the period from 2007 to 2017, Gestational trophoblastic disease constituted only $0.35 \%$ of the total number (35 patients).

The mean age was 32.1 years (range 20-55 years) (SD \pm 9.9 ). Among the 35 cases, 28 patients (80\%) were below the age of 40 and 7 females (20\%) were above age of 40 year.

Seven patients $(20 \%)$ had history of multiple previous abortions. One patient (2.9\%) has positive family history of V.M. "her mother".

Table 1: demographic features at initial presentation

\begin{tabular}{|l|l|c|c|}
\hline \multicolumn{2}{|c|}{} & Count & \% \\
\hline \multirow{2}{*}{ Age Group } & $\leq 40$ & 27 & 77.1 \\
& $>40$ & 8 & 22.9 \\
\hline \multirow{2}{*}{ Family History } & No & 34 & 97.1 \\
& Yes & 1 & 2.9 \\
\hline \multirow{2}{*}{ Abortion } & No & 28 & 80.0 \\
& Yes & 7 & 20.0 \\
\hline
\end{tabular}

Thirty three patients (94.3\%) were subjected to evacuation primarily except for 2 patients, one biopsy was obtained from lung mets and the other was very risky of severe bleeding. Most of these patients was evacuated by D\&C, or suction, but 9 patients (25.7\%) was subjected to hysterectomy, 6 patients were old and completed their families, while one had complication during D and $\mathrm{C}$, one had tumor infiltrating whole thickness of uterus and the last had severe uncontrolled bleeding. Antecedent pregnancy was abortion in 9 patients (25.7\%), vesicular mole in $19(54.3 \%)$ patients and 7 patients (20\%) presented with antecedent full term pregnancy. By reviewing the histopathology, molar pregnancy was present in 14 case " 4 partial (11.4\%) and 10 complete (28.6\%)" , 11 histopathology specimens were invasive mole $(31.4 \%)$, while 9 (25.7\%) patients had choriocarcinoma, Only 1 patient $(2.9 \%)$ had placental site trophoblastic disease. According to FIGO Prognostic Scoring for 
Gestational Trophoblastic Disease; 26 patients $(74.3 \%)$ were classified as low risk $\{$ score $\leq 6\}$, and 9 patients $(25.7 \%)$ were classified as high risk \{score $\geq 7\}$. In low risk patients, 30.8\% was kept under follow up while, $69.2 \%$ received methotrexate as first line chemotherapy, $61.1 \%$ of them achieved complete remission, while $38.9 \%$ were refractory, all achieved complete response on the $2^{\text {nd }}$ line chemotherapy. The majority of high risk patients received EMACO as first line chemotherapy with (66.7\%) complete response and 2 cases of early death due to bad general condition, and high tumor burden at time of presentation; while Methotrexate wasn't effective. The resistance to first line chemotherapy in this study was correlated to many factors, but only initial high B-hCG level $(\geq 10000 \mathrm{mIU} / \mathrm{ml})$ was statistically significant risk factor ( $p$ value: 0.05 ), while early stage disease was a good prognostic factor but $\mathrm{p}$ value was $(0.08)$.

Table 2: initial assessment

\begin{tabular}{|l|l|c|c|}
\hline \multicolumn{2}{|c|}{ Content of Last Conception } & Count & \% \\
\hline \multirow{5}{*}{ Biopsy } & Abortion & 9 & 25.7 \\
& Mole & 19 & 54.3 \\
& Term & 7 & 20.0 \\
\hline \multirow{5}{*}{ Histology } & Biopsy from lung & 1 & 2.9 \\
& D\&C & 22 & 62.9 \\
& Not done & 1 & 2.9 \\
& S\&E & 4 & 11.4 \\
& TAH +BSO & 5 & 14.3 \\
\hline \multirow{5}{*}{ PS at presentation } & Choriocarcinoma & 9 & 25.7 \\
& Invasive Mole & 11 & 31.4 \\
& PSTT & 1 & 2.9 \\
& Vascular Mole Partial & 4 & 11.4 \\
& Vesicular Mole Complete & 9 & 28.6 \\
\hline & O WHO & 23 & 25.7 \\
& I WHO & 1 & 65.7 \\
& II WHO & 5.7 \\
\hline
\end{tabular}

Table 3: causes and types of intervention

\begin{tabular}{|c|c|c|c|}
\hline & & Count & $\%$ \\
\hline \multicolumn{4}{|l|}{ Cause of intervention } \\
\hline \multirow{2}{*}{ Mets } & No & 27 & 77.1 \\
\hline & Yes & 8 & 22.9 \\
\hline \multirow{2}{*}{ Choriocarcinoma } & No & 29 & 82.9 \\
\hline & Yes & 6 & 17.1 \\
\hline \multirow{2}{*}{ Increased BhCG } & No & 18 & 51.4 \\
\hline & Yes & 17 & 48.6 \\
\hline \multirow{2}{*}{ Residual } & No & 28 & 80.0 \\
\hline & Yes & 7 & 20.0 \\
\hline \multirow{2}{*}{ Bleeding } & No & 28 & 80.0 \\
\hline & Yes & 7 & 20.0 \\
\hline \multicolumn{4}{|l|}{ Type of intervention } \\
\hline \multirow{4}{*}{ Type of intervention } & $2 \mathrm{D} \& \mathrm{C}$--> chemotherapy & 10 & 28.6 \\
\hline & Chemotherapy & 16 & 45.7 \\
\hline & FOLLOW UP & 5 & 14.3 \\
\hline & Hysterectomy & 3 & 8.6 \\
\hline \multicolumn{4}{|l|}{ Chemotherapy arm } \\
\hline \multirow{2}{*}{ Chemotherapy arm } & No & 9 & 25.7 \\
\hline & Yes & 26 & 74.3 \\
\hline
\end{tabular}

Table 4: univariant analysis of risk factors and its relation to resistance to $1^{\text {st }}$ line chemotherapy 


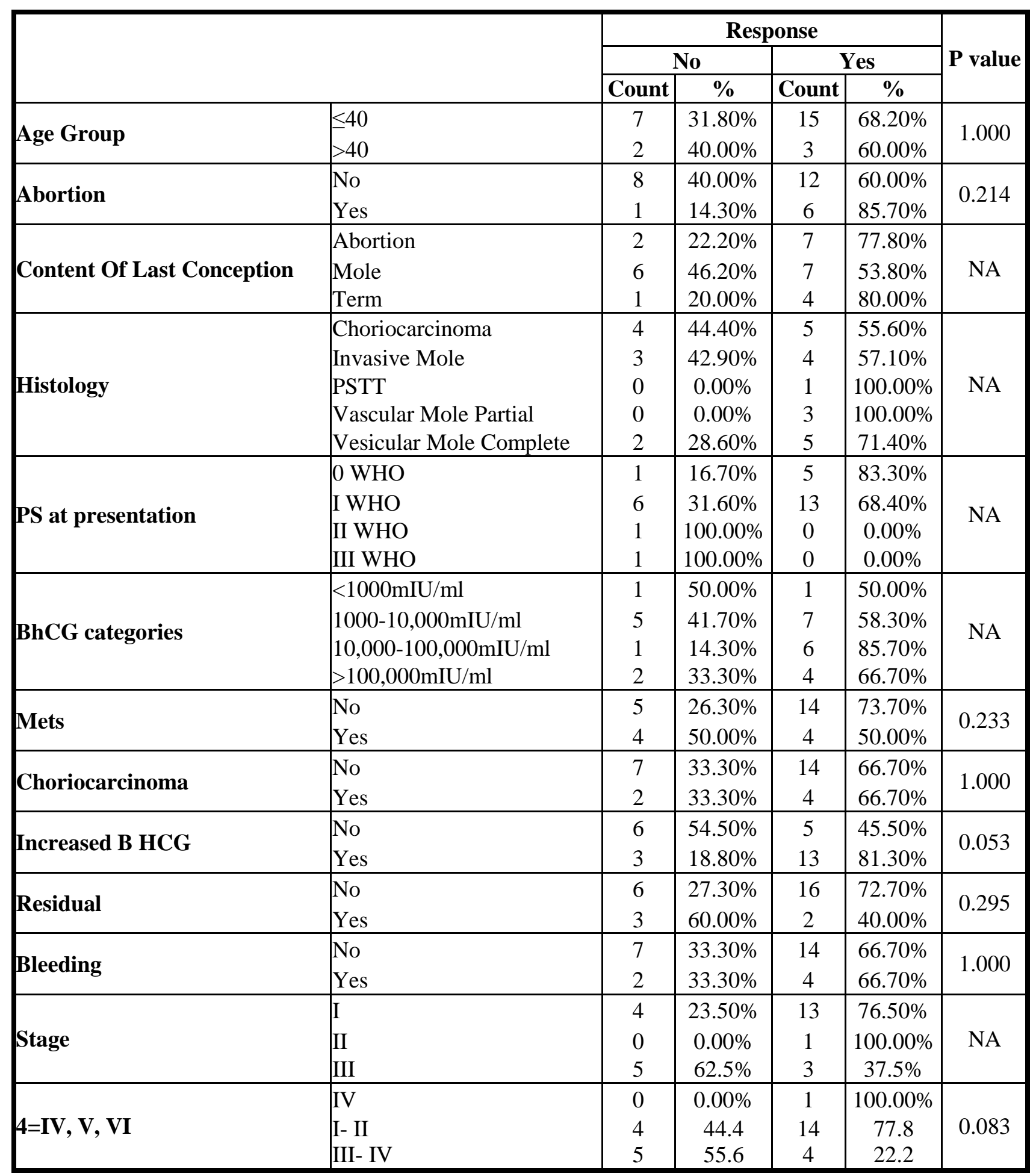

Table 5: univariant analysis of FIGO score components and its relation to resistance to $1^{\text {st }}$ line chemotherapy 


\begin{tabular}{|c|c|c|c|c|c|c|}
\hline \multirow{3}{*}{\multicolumn{2}{|c|}{ FIGO Score. }} & \multicolumn{4}{|c|}{ Response } & \multirow{5}{*}{$\begin{array}{c}\text { P-value } \\
1.000\end{array}$} \\
\hline & & \multicolumn{2}{|c|}{ No } & \multicolumn{2}{|c|}{ Yes } & \\
\hline & & Count & $\%$ & Count & $\%$ & \\
\hline \multirow{2}{*}{ (Age) } & 0 & 7 & 33.3 & 14 & 66.7 & \\
\hline & 1 & 2 & 33.3 & 4 & 66.7 & \\
\hline \multirow{3}{*}{ Previous Conception } & 0 & 4 & 26.7 & 11 & 73.3 & \multirow{3}{*}{ NA } \\
\hline & 1 & 2 & 40.0 & 3 & 60.0 & \\
\hline & 2 & 2 & 33.3 & 4 & 66.7 & \\
\hline \multirow{4}{*}{ Interval From previous conception } & 0 & 5 & 27.8 & 13 & 72.2 & \multirow{4}{*}{ NA } \\
\hline & 1 & 0 & 0.0 & 4 & 100.0 & \\
\hline & 2 & 1 & 50.0 & 1 & 50.0 & \\
\hline & 4 & 2 & 100.0 & 0 & 0.0 & \\
\hline \multirow{4}{*}{ Pretreatment HCG } & 0 & 0 & 0.0 & 3 & 100.0 & \multirow{4}{*}{ NA } \\
\hline & 1 & 2 & 20.0 & 8 & 80.0 & \\
\hline & 2 & 4 & 50.0 & 4 & 50.0 & \\
\hline & 4 & 3 & 50.0 & 3 & 50.0 & \\
\hline \multirow{3}{*}{ Largest Tumor Size } & 0 & 3 & 33.3 & 6 & 66.7 & \multirow{3}{*}{ NA } \\
\hline & 1 & 1 & 16.7 & 5 & 83.3 & \\
\hline & 2 & 4 & 80.0 & 1 & 20.0 & \\
\hline \multirow{2}{*}{ Site of Mets } & 0 & 4 & 57.1 & 3 & 42.9 & \multirow{6}{*}{ NA } \\
\hline & 4 & 1 & 50.0 & 1 & 50.0 & \\
\hline \multirow{2}{*}{ Number of Mets } & 1 & 1 & 33.3 & 2 & 66.7 & \\
\hline & 4 & 3 & 60.0 & 2 & 40.0 & \\
\hline \multirow{2}{*}{ Previous Chemotherapy } & 1 & 2 & 100.0 & 0 & 0.0 & \\
\hline & 2 & 1 & 100.0 & 0 & 0.0 & \\
\hline
\end{tabular}

\section{DISCUSSION}

The reported incidence of GTD varies widely worldwide, from a 23 per 100,000 pregnancies (Paraguay) to 1,299 per 100,000 pregnancies in Indonesia. In USA they account for only less than $1 \%$ of all gynecological tumors accounting for about 1 pregnancy out of $1,000^{(4)}$. This divergence in prevalence may be due to the discrepancies between race, local medical conditions, and educational level. Moreover, incidence rate of GTN was less well known because most of the studies were hospital based rather than population based ${ }^{(\mathbf{1 2})}$. In this study, GTD represented $0.4 \%$ of the total number of cancer cases presented to Al Husien University Hospital during the period from 2007 to 2017. The mean age of our patients was 32.1 years which is slightly higher than results published by Abd El Raouf ${ }^{(3)}$, slightly lower than the findings reported by Sita-Lumsden et al. ${ }^{(9)}$ in which the mean age was 35 years, but not very similar to data published by Kaye et al. ${ }^{(13)}$ from Uganda who reported that most of his cases occurred below 20 years or above 35 years and this may reflect a real difference or it shows the heterogeneity among different countries.Twenty eight $(80 \%)$ patients in our study were below the age of 40 and 7 patients (20\%) were above 40 years, these findings are close to a previous report that
$80 \%$ of GTD cases were at age group between 2039 years, $16 \%$ were below 20 years and only $4 \%$ of patients were above 40 years $^{(1)}$, and also close to results of Abd El Raouf (3) where 18\% of patients were over the age of $40^{(3)}$. Most of our antecedent pregnancies were molar pregnancies $(54.3 \%)$, followed by abortion (25.7\%), which is close to results of Kuyumcuoglu et al. ${ }^{\text {(14). }}$.

By reviewing the histopathology, molar pregnancy was $40 \%$, invasive mole was $31.4 \%$, while choriocarcinoma was $25.7 \%$, Only $2.9 \%$ was placental site trophoblastic disease. This finding does not agree with a previous report from Mansoura University Hospital in 2011, in which choriocarcinoma was about $(55.5 \%)^{(15)}$ and Sebire et al. ${ }^{(16)}$ who also reported that choriocarcinoma was the commonest histopathology. However; Essel et al. ${ }^{\left({ }^{17)}\right.}$ reported that persistent GTN was the commonest histopathology (54\%), but they also reported that invasive mole was very uncommon (4\%). Lung was the commonest site $(73 \%)$ of metastatic sites. A close finding was reported by Kumar et al. ${ }^{(18)}$ who found that lung was the commonest site of metastases and represented 65\% of metastatic sites and Essel et al. ${ }^{(17)}$ where lung metastasis was $(65 \%)$. In our study, 26 patients 
(74.3\%) were low risk $\{$ score $\leq 6\}$, and 9 patients $(25.7 \%)$ were high risk $\{$ score $\geq 7\}$. Gestational trophoblastic neoplasia was highly responsive to chemotherapy and prognosis was excellent following treatment, especially in low-risk patients ${ }^{(19)}$. However, resistance to first line chemotherapy was reported by Newlands et al. ${ }^{(20)}$ to occur in $33 \%$ of low risk cases and about $10 \%$ of high risk cases, also Macdonald et al. (21) reported $44 \%$ chemotherapy resistance in low risk group. In the current study, $38.9 \%$ of low risk cases were resistant to first line chemotherapy and about $28.6 \%$ was of high risk cases which slightly higher than data published by Newlands et al. (20), but less than Macdonald results ${ }^{(21)}$.Sixty six percent of high risk cases (4 out of 6 patients), who received EMACO combination chemotherapy, achieved complete response. This figure coincides with the study reported by Shen et al. ${ }^{(22)}$ who reported complete remission rate of $67 \%$ and $33 \%$ were resistant. The highest complete response rate was reported by Liu et al. ${ }^{(23)}$ reported $67.9 \%$ complete response to EMA-CO alone added to $14.8 \%$ achieved by EMACO with surgery Liu et al. ${ }^{(23)}$. The remaining 2 patients died early after initiating chemotherapy. This early death was studied by Alifrangis et al. ${ }^{(24)}$ who noticed that it's more common in patients with high risk, high burden disease, comorbidities and misdiagnosis as GTN and they concluded that the use of genetic analysis to confirm diagnosis in patients with abnormal presentation, and the use of induction low dose etoposide-cisplatin for those patients is linked to decreased rate of early deaths and improved overall survival. The resistance to first line chemotherapy in this study can be correlated to many factors, but only initial high BhCG level $(\geq 10000 \mathrm{mIU} / \mathrm{ml})$ was statistically significant risk factor ( $\mathrm{p}$ value: 0.05 ), while early stage disease was a good prognostic factor but $p$ value was (0.08). These findings were supported by data published by Bagshawe ${ }^{(25)}$ who showed that there was a significant correlation of chemotherapy response to initial $\mathrm{B}-\mathrm{hCG}(\mathrm{p}=0.001)$. Choriocarcinoma pathology and HCG clearance $\leq$ 0.37 I.U/day were major independent predictive factors for methotrexate resistance risk as reported by You et al. ${ }^{(26)}$.The commonest chemotherapy toxicity was hematological toxicity (neutropenia) occurred in $(32.1 \%)$ of patients, reported mainly, \& was more severe (G III: IV) with EMACO. The $2^{\text {nd }}$ most common toxicity was mucositis reported in $27.6 \%$ of patients, which was more common and more severe with EMA-CO. With EMA-CO, liver toxicity was reported in (30\%) of patients, while $\mathrm{G}$ III anemia in (20\%). These findings are consistent with Maestá et al. (27). While Lybol et al. (28) reported anemia in $28.2 \%$ of patient treated with EMA-CO, neutropenia in $48.5 \%$, hepatotoxicity in $16.5 \%$, and mucositis $9.7 \%$. This little rise of toxicity rates in our results can be attributed to low socio-economics and bad general condition of our patients, while this noted decrease in our rate of reported anemia is because we don't record anemia except if G III or IV.

Surgical procedures may be good adjuncts to chemotherapy in properly selected cases as the majority of women with GTN are young and wish to preserve their fertility. 9 patients $(25.7 \%)$ was subjected to hysterectomy, 6 patients were old, \& completed their families, while one had complication during $\mathrm{D} \& \mathrm{C}$, one had tumor infiltrating whole thickness of uterus, $\&$ the last has severe uncontrolled bleeding. Keeping with Eysbouts et al. (29), and Bolz et al. (30) recommendations as they suggested that Primary hysterectomy should mainly be considered in older patients with localized disease and no desire to preserve fertility, whereas patients with chemotherapy-resistant disease may benefit from additional hysterectomy, especially when disease is localized.

The overall survival rates for patients with high-risk GTN are now running as high as 95\%, while in low risk GTN The overall complete remission rate is close to $100 \%$, which is close to our result in low risk group, while in high risk group our overall survival was significantly lower, reaching down to $55.6 \%$, this may be due to the low number of our high risk patients, large proportion of bad general condition patients, and the use of methotrexate single agent in one third of them which was proved ineffective.

\section{CONCLUSION}

GTN is a very rare and heterogeneous group of disease, though cure rate even in advanced staging and high risk patients is considerably high with appropriate treatment. FIGO scoring system is a good predictive tool in Stratifying patients to risk groups, thus guiding us for more appropriate choice of single versus multi-agent chemotherapy, although it's complicated and need some simplification.

Hysterectomy can be radical treatment in patients with localized disease who don't want to preserve fertility. Methotrexate is a very chemotherapy to start with in low risk GTN, while it has very low effect in high risk patients, in those 
patients with high risk disease EMA-CO is the best option, except in patient with bad general, and high disease burden where there's considerable cases of early deaths.

We have to report that this retrospective study represented a single center experience and had relatively small number of cases.

\section{REFERENCES}

1. Strohl AE and Lurain JR (2014): Clinical Epidemiology of Gestational Trophoblastic Disease. Current Obstetrics and Gynecology Reports, 3(1):40-3.

2. Tasha I, Kroi E, Karameta A, Shahinaj R and Manoku N (2010): Prevalence of gestational trophoblastic disease in ectopic pregnancy. J Prenat Med., 4(2): 26-29.

3. Abd El Raouf O. (2014): Clinical analysis of molar pregnancy in egyptian population, AAMJ. 12: 4.

4. Altieri A, Franceschi S, Ferlay J, Smith J, La Vecchia C (2003): Epidemiology and aetiology of gestational trophoblastic diseases. Lancet Oncol., 4(11):670-8.

5. Kim SJ1, Lee C, Kwon SY, Na YJ, Oh YK, Kim CJ (2004): Studying changes in the incidence, diagnosis and management of GTD.

https://www.ncbi.nlm.nih.gov/pubmed/154 57855

6. Lurain J (2010): Gestational trophoblastic disease I: epidemiology, pathology, clinical presentation and diagnosis of gestational trophoblastic disease, and management of hydatidiform mole. Am. J. Obstet. Gynecol., 203:531-539.

7. Seckl MJ, Sebire NJ, Fisher RA, Golfier F, Massuger L, Sessa C (2013): ESMO guidelines working group. Gestational trophoblastic disease: ESMO clinical practice guidelines for diagnosis, treatment and follow-up. Ann. Oncol., 24:vi39-vi50.

8. Braga A, Torres B, Burlá M, Maestá I, Yazaki SS, Lin L, Madi JM, Maurício EU, Kevin V, Elias M, Berkowitz RS (2016): Is chemotherapy necessary for patients with molar pregnancy and human chorionic gonadotropin serum levels raised but falling at 6 months after uterine evacuation? Gynecol. Oncol. , 143(3):558-564.
9. Sita-Lumsden A, Short D, Lindsay I et al. (2012): Treatment outcomes for 618 women with gestational trophoblastic tumours following a molar pregnancy at the Charing Cross Hospital. $\mathrm{Br}$ J Cancer, 107:1810Y1814.

10. FIGO Oncology Committee (2002): FIGO staging for gestational trophoblastic neoplasia 2000 . https://www.ncbi.nlm.nih.gov/pubmed/120 65144

11. Ngan HY, Bender H, Benedet JL, Jones H, Montruccoli GC, Pecorelli S. (2003): Gestational trophoblastic neoplasia, FIGO 2000 staging and classification. Int $\mathrm{J}$ Gynaecol Obstet. ,83(1):175-7.

12. Sun $R$, Zhang $Y$, Zheng $W$, Tian $Q$, An $R$ and Xue Y (2016): Clinical Characteristics of Gestational Trophoblastic Neoplasia: A 15Year Hospital-Based Study. Int J Gynecol Cancer, 26(1): 216-221.

13. Kaye DK (2002): Gestational trophoblastic disease following complete hydatidiformmodle in Mulago Hospital, Kampala, Uganda. African Health Science, 2: 47- 51 .

14. Kuyumcuoglu U, Guzel A, Celik Y et al. (2011): Risk factors for persistent gestational trophoblastic neoplasia. Journal of Experimental Therapeutics and Oncology,9:81-84.

15. Reda Abd El hady H, Eman T, Hend S et al. (2011): Chemo-resistant gestational trophoblastic neoplasia, 5-years experience of Mansoura University Hospital, Egypt Journal of Obstetrics and Gynecology, 1: 153-157.

16. Sebire NJ and Lindsay I (2010): Current Issues in thepathology of gestational trophoblastic tumors. Fetal and Pediatric Pathology, 29: 30-44.

17. Essel KG, Shafer A, Bruegl A, Gershenson DM, Drury LK, BA, Ramondetta LM, Wendel RN and Jubilee B (2018): Complete Resection Is Essential in the Surgical Treatment of Gestational Trophoblastic Neoplasia. https://www.ncbi.nlm.nih.gov/pubmed/301 57165 
18. Kumar J, Ilancheran A andRatnam $S$ (1988): Pulmonary metastases in gestational trophoblastic disease: A review of 97 cases. British Journal of Obstetrics and Gynecology, 70:74.

19. Brown J, Wendel RN, Michael JS, Julian S (2016): 15 years of progress in gestational trophoblastic disease: Scoring, standardization, and salvage. DOI: 10.1016/j.ygyno.2016.08.330

20. Newlands ES, Mulholland PJ et al. (2000): Etoposide and cisplatin/etoposide, methotrexate, and actinomycin D (EMA) chemotherapy for patients with high-risk gestational trophoblastic tumors refractory to EMA/cyclophosphamide and vincristine chemotherapy. Journal of Clinical Oncology, 18:854-859.

21. Macdonald MC, Hancock BW, Winter MC, Coleman RE, Tidy JA (2016): Management and Outcomes of Patients with Stage I and IIIl Low- Risk Gestational Trophoblastic Neoplasia Treated in Sheffield, UK, from 1997-2006. J Reprod Med,. 61(7-8):341-346.

22. Shen T, Chen LL, Qin JL, Wang XY, Cheng XD, Xie X, Lyu WG (2018): [EMA/CO regimen for chemotherapy 24 patients with ultra high-risk gestational trophoblastic neoplasia]. Zhonghua Fu Chan Ke Za Zhi., 53(6):371-376.

23. Liu W1, Zhao W, Zhang YQ, Huang XF (2018): Curative effects and influenced factors of EMA-CO as an initial regimen for the treatment of high-risk gestational trophoblastic neoplasia]. Zhonghua Yi Xue Za Zhi. ,98(47):3896-3899.

24. Alifrangis C, Agarwal R, Short D, Fisher R A, Sebire N, Savage PM, Seckl MJ (2013): EMA/CO for high-risk gestational trophoblastic neoplasia: good outcomes with induction low-dose etoposide-cisplatin and genetic analysis. J Clin Oncol., 31(2):280-6.

25. Bagshawe KD (1976): Risk and prognostic factors in trophoblastic neoplasia Cancer, 38: 1373-1385.

26. You B, You B, Pollet-Villard M et al. (2010): Predictive values of hCG clearance for risk of methotrexate resistance in low-risk gestational trophoblastic neoplasias. https://academic.oup.com/annonc/article/2 $1 / 8 / 1643 / 153884$

27. Maestá L et al. (2018): Effectiveness and toxicity of first-line methotrexate chemotherapy in low-risk postmolar gestational trophoblastic neoplasia. https://www.ncbi.nlm.nih.gov/pubmed/290 92742

28. Lybol C, Thomas CM, Blanken EA, Sweep FC, Verheijen RH, Westermann AM, Boere IA, Reyners AK, Massuger LF, van Hoesel RQ, Ottevanger PB (2013) Comparing cisplatin-based combination chemotherapy with EMA/CO chemotherapy for the treatment of high risk gestational trophoblastic neoplasia. Eur J Cancer., 49(4):860-7.

29. Eysbouts YK et al. (2017): The added value of hysterectomy in the management of gestational trophoblastic neoplasia. https://www.ncbi.nlm.nih.gov/pubmed/283 90821

30. Bolze $\mathbf{P}$ A, Mélodie Mathe, Touria Hajri, Benoit You, YohannDabi, Anne-Marie Schott, Sophie Patrier, Jérôme Massardier, François Golfier (2018): First-line hysterectomy for women with low-risk non-metastatic gestational trophoblastic neoplasia no longer wishing to conceive. Gynecologic Oncology, 150 : 282-287. 